\title{
Dynamic Causal Modeling of Effective Connectivity During Anger Experience in Healthy Young Men: 7T Magnetic Resonance Imaging Study
}

\author{
Ji-Woo Seok ${ }^{1,2}$ and Chaejoon Cheong ${ }^{2}$ \\ 1 Department of Counseling Psychology, Honam University, Kwangju, South Korea \\ ${ }^{2}$ Bioimaging Research Team, Korea Basic Science Institute, Cheongju, South Korea
}

\section{KEYWORDS}

anger processing;

dynamic causal modeling;

effective connectivity;

functional magnetic

resonance imaging;

film clip

Little is known about how anger-associated brain regions integrate and modulate external input. Therefore, we investigated the neural connectivity architecture of anger processing using a dynamic causal modeling (DCM) approach. Thirteen subjects underwent functional magnetic resonance imaging (fMRI) while viewing anger-inducing film clips. Conventional fMRI and DCM analyses were conducted to identify a dominant connectivity model. Viewing anger-inducing film clips led to activation in the left superior temporal gyrus, left insula, and left orbitofrontal cortex (OFC). The results of a group-level comparison of eight connectivity models based on conventional fMRI findings showed superiority of the model including reciprocal effective connectivities between the left insula, left superior temporal gyrus, and left orbitofrontal gyrus and bottom-up connectivity from the left superior temporal gyrus to the left orbitofrontal gyrus. Positive coupling effects were identified for connectivities between the left superior temporal gyrus and left insula and the left superior temporal gyrus and left OFC. A negative coupling effect was identified for connectivity between the left OFC and left insula. In conclusion, we propose a model of effective connectivity associated with the anger experience based on dynamic causal modeling. The findings have implications for various psychiatric disorders related to abnormalities in anger processing.

\section{INTRODUCTION}

Anger is an intense, uncomfortable emotional response to perceived provocation, insult, or offense (Videbeck, 2013). Anger contributes adaptively to survival by alerting an individual to potential or actual problems on an individual, interpersonal, or societal scale; however, uncontrolled anger can lead to negative effects on personal or social well-being (Novaco, 1976). Neuroscientists as well as social, clinical, and personality psychologists are deeply interested in understanding the neural mechanisms of anger processing and the biological factors that predispose individuals to aggression (Denson, Pedersen, Ronquillo, \& Nandy, 2009).

A number of neuroimaging studies have investigated the neural substrates of anger in healthy subjects (Lindquist, Wager, Kober, BlissMoreau, \& Barrett, 2012; Murphy, Nimmo-Smith, \& Lawrence, 2003;

Corresponding author: Chaejoon Cheong, Bioimaging Research Team, Korea Basic Science Institute, 162 Yeongudanji-ro, Cheongju 28119, Republic of Korea. E-mail: cheong@kbsi.re.kr 
Phan, Wager, Taylor, \& Liberzon, 2002; Wager et al., 2008). Studies on anger processing can be classified as investigations of anger experience or of anger perception. Anger perception involves observation of and judgments about the normative content of a stimulus, such as whether a picture of a facial expression resembles anger, fear, or disgust. In contrast, anger experience refers to the generation of angry feelings in response to pictures, sounds, memories, or other stimuli (Lindquist et al., 2012). Until now, most studies on anger processing have examined anger perception using experimental paradigms such as the facial judgment task or facial matching task, rather than tasks that generate an anger experience. Effective connectivity within the cortical network has also been examined for anger perception (Bakke, 2012; Fairhall \& Ishai, 2006). However, there have been very few such studies on anger processing including not only anger perception but also experience. Several meta-analyses of neuroimaging studies on emotion concluded that regions and patterns of brain activation differ across various emotional experiences and perceptions (Murphy et al., 2003; Phan et al., 2002; Wager et al., 2008). Therefore, to examine the effective connectivity of neural substrates related to overall anger processing, a paradigm including anger experience and perception should be used. There are several established techniques for eliciting emotional processing, including exposure to emotional images, autobiographical recollection, mental imagery, and emotional film clips. Compared to other methods, exposure to an emotional film clip has several benefits (Schaefer, Nils, Sanchez, \& Philippot, 2010), in that film clips can evoke vivid feelings and elicit strong subjective and physiological changes. Accordingly, we used film clips to identify overall anger processing including anger perception and anger experience in the study.

Previous research has suggested that anger processing is a complex interaction among perception, experience, and regulation, related to different areas of the brain (Lindquist et al., 2012; Murphy et al., 2003; Phan et al., 2002; Wager et al., 2008). Anger perception comprises processing of social signals, such as those derived from others' faces, voices, gestures, and contextual information that individuals use to interpret others' behaviors (Baldwin, 1992; McArthur \& Baron, 1983). Among other brain regions, the superior temporal gyri (STGs) are mainly engaged when processing various social signals (Adolphs, 2003; Allison, Puce, \& McCarthy, 2000; Paulus, Feinstein, Leland, \& Simmons, 2005; Singer, Kiebel, Winston, Dolan, \& Frith, 2004; Xu, Gannon, Emmorey, Smith, \& Braun, 2009). The anger experience is related to viscerotropic sensory responses enabling the individual to be in a state of readiness to take specific action (Lampert et al., 2002; Lampert, 2016; Mostofsky, Penner, \& Mittleman, 2014; Suls, 2013; Taggart \& Lambiase, 2011). Some studies have suggested that the anterior insula plays a key role in brain-heart interactions by controlling the cardiovascular sympathetic response (Critchley, 2009; Nagai, Hoshide, \& Kario, 2010; Oppenheimer, 2006). Recently, a neuroanatomical study suggested two main functions of the insula, including integrating bottom-up interoceptive signals with top-down predictions to produce a present awareness state and contributing descending predictions to visceral systems that provide a point of reference for autonomic reflexes $(\mathrm{Gu}$, Hof, Friston, \& Fan, 2013). Anger regulation includes directing behav- ior to a target by integrating the impulse to express the anger and the need to suppress any aggressive behavior in the current circumstances. The orbitofrontal cortex (OFC) is known to participate in this process (Bechara, Damasio, \& Damasio, 2000; Grafman et al., 1996; Lindquist et al., 2012). However, conventional functional imaging analyses (i.e., functional specialization) have not fully elucidated the organization of these areas or how they integrate and modulate incoming information. Recently, to examine the organization, interrelationship, and integrated performance of functionally-specialized areas, several approaches have been developed, including functional connectivity and effective connectivity (Friston, 1994; Friston, Harrison, \& Penny, 2003; Horwitz, 2003). Functional connectivity measures the temporal correlation of activity between brain areas, whereas effective connectivity measures directed influences of a brain area on another. Thus, effective connectivity can provide information associated with the causal processes that operate in brain function. In this study, we used the dynamic causal modeling (DCM) method to identify effective connectivity.

The DCM is a method for the interpretation of functional neuroimaging data that was developed to estimate intrinsic coupling (taskindependent interactions) within a set of regions and to determine how coupling is influenced by experimental factors (e.g., time or context) (Friston et al., 2003). The DCM approach is used to infer causal relationships from functional imaging data or to determine a model that can explain a set of empirical observations among a predefined causal model set of alternatives. To determine the best model, the combined neuronal and hemodynamic parameters of DCM are estimated from measured blood oxygen level-dependent (BOLD) signals using iterative Bayesian estimation (Friston et al., 2003; Stephan, Weiskopf, Drysdale, Robinson, \& Friston, 2007).

Recently, using the DCM method, Mazzola et al. (2016) studied the dynamic interplay between the insula and the STG when the participants encountered situations involving anger and found that there is reciprocal connectivity between these areas. However, they focused on the neural network related to affect, not to cognition, during emotional processing. Studies on emotion processing have suggested that affect and cognition are mediated by separate but interacting systems in the brain (LeDoux, 1989; Lemerise \& Arsenio, 2000; Murphy et al., 2003). Hence, in this study we extended the results of previous studies to investigate the connectivity pattern subserving communication between affective and cognitive systems during anger processing. That is, the aim of this study was to investigate the connectivity pattern among brain areas related to anger perception, experience, and regulation (i.e., the insula, STG, and OFC) during anger processing. Specifically, based on the previous study which found that the insula plays a key role in the integration of bottom-up and top-down emotion generation $(\mathrm{Gu}$ et al., 2013), we hypothesized that the insula may be a hub of emotion processing in connecting the STG and the OFC and that there would be negative effective connectivity between the OFC and insula. To this end, we used functional magnetic resonance imaging (fMRI) combined with the DCM approach to investigate the neuronal interactions of different brain regions associated with anger and to determine how these interactions are modulated by anger-evoking stimuli. 


\section{MATERIALS AND METHODS}

\section{Participants}

Thirteen male subjects participated in the fMRI experiment $\left(M_{\text {age }}=24.2 \pm 2.26\right.$ years; range $=21-27$ years $)$. We recruited only male subjects because emotionally-evocative visual stimuli can vary in their effects depending on sex and age. The exclusion criteria included a history of head injury, drug or alcohol abuse, and any significant psychiatric condition as assessed by the Structured Clinical Interview for the Diagnostic and Statistical Manual of Mental Disorders version IV (First, Spitzer, \& Gibbon, 2002). All subjects provided written informed consent for study participation after being fully informed about the experimental procedure. The experimental protocol was approved by the local institutional review board (P01-201602-11-002).

\section{Film Stimuli}

We searched for anger-inducing film clips from movies, drama, news, and documentaries in advance, and consequently, 20 clips were selected. Anger-evoking film clips conveyed stories regarding child abuse, mocking a person with disabilities, racism, unfair treatment, and bullying. We conducted a pilot experiment with 52 men using these clips. These men were shown 20 film clips for $90 \mathrm{~s}$ each, in a randomized order. As a result, the five clips with the highest group-average ratings of anger were chosen. Most participants $(96.06 \pm 4.75 \%)$ reported that they experienced anger watching these clips, and the intensity was 3.29 \pm 1.19 on a 6-point Likert scale (from $0=$ not angry at all to $5=e x$ tremely angry). The film clips for the fMRI study included five neutral clips with nonaffective nature scenes and the five anger-evoking clips. The neutral clips were matched in terms of color and hue.

\section{Experimental Paradigm and Procedure}

The fMRI task comprised two conditions: a neutral condition and an anger-inducing condition. Each condition was composed of five $30 \mathrm{~s}$ blocks. A $12 \mathrm{~s}$ interstimulus interval preceded each block. Each block was presented randomly to eliminate order effects. The total scanning session required approximately $7 \mathrm{~min}$ (see Figure 1).

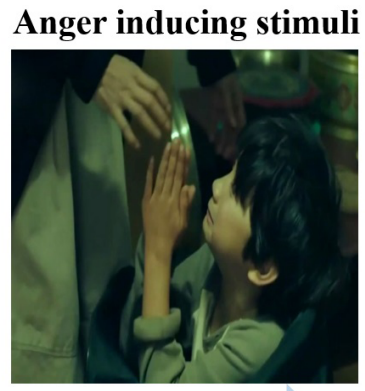

$30 \mathrm{~s}$

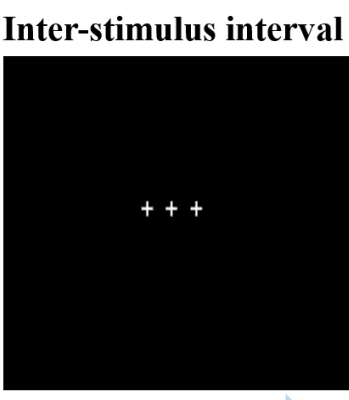

$12 \mathrm{~s}$

\section{Self-Report of Subjective Anger}

After completing the fMRI scanning, the participants watched the same film clips that were shown during the fMRI scanning, and they were instructed to respond to the following questions in order to evaluate suitability and effectiveness. At first, they were required to answer whether anger was evoked while watching the film clips. Second, they were asked to evaluate the anger intensity of each film clip on a scale from 0 to $5(0=$ not angry at all to $5=$ extremely angry $)$ and to indicate the sections that evoked the most intense emotions. Finally, they were required to report any emotions (i.e., sadness, happiness, fear, disgust, surprise) that they may have experienced other than anger during their exposure to each film clip.

\section{fMRI Acquisition}

Imaging was performed using a 7.0-T Philips Achieva MR scanner equipped with a 32-channel NOVA head coil. The parameters for scanning were as follows: repetition time $(\mathrm{TR})=2000 \mathrm{~ms}$; echo time $(\mathrm{TE})=17 \mathrm{~ms}$; flip angle $=70^{\circ}$; field of view $=192 \times 198 \times 72 \mathrm{~mm}^{3}$; matrix $=128 \times 129$; slice thickness $=3 \mathrm{~mm}$; and in-plane resolution $=1.5 \times 1.5 \times 3 \mathrm{~mm}^{3}$. T1-weighted anatomical images were obtained using a $3 \mathrm{D}$ fast field echo sequence with the following parameters: $\mathrm{TR}=5.5 \mathrm{~s} ; \mathrm{TE}=2.6 \mathrm{~ms}$; flip angle $=7^{\circ}$; field of view $=234 \times 234 \mathrm{~mm}^{2}$; voxel size $=0.67 \times 0.67 \times 0.67 \mathrm{~mm}^{3}$.

\section{Analysis of fMRI Processing}

To induce emotions more vividly, we used film clips, not pictures or scripts, in this study. However, some researchers have contested that film clips may elicit "blends" of emotions rather than "pure" ones (Hemenover \& Schimmack, 2007; Larsen, McGraw, \& Cacioppo, 2001; Schimmack, 2001). To solve this problem, we excluded the data obtained from those clips that did not evoke anger or induced emotions other than anger from the analysis.

The first three image volumes were discarded to avoid instability of the initial MRI signal. Thereafter, functional data were processed using the statistical parametric mapping program SPM 12 (www.fil. ion.ucl.ac.uk/spm). The images were corrected for slice acquisition timing and then realigned to the first functional image. Anatomical

\section{FIGURE 1.}

The experimental paradigm for the fMRl imaging.

\section{Neutral stimuli}

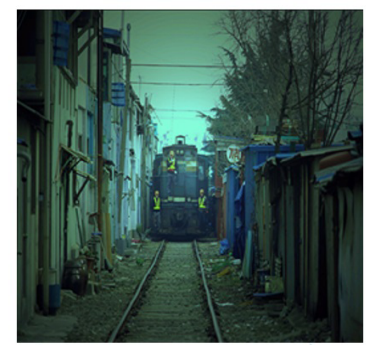

$30 \mathrm{~s}$ 
images were coregistered to the mean echo-planar image, and the coregistered images were subsequently normalized into the standard Montreal Neurological Institute (MNI) template. Normalized images were smoothed with an $8 \mathrm{~mm}$ Gaussian kernel. A design matrix modeling the anger-evoking and neutral conditions was constructed for each subject. A contrast was performed for each subject to identify anger-specific neural substrates, using $t$-tests to compare the angerevoking and neutral conditions. The results were input to a random effects analysis of group inferences. Activations were considered significant at $p<.05$ (family-wise error [FWE]-corrected at voxel-level) with a minimum cluster size of $k=10$. The brain coordinates in the fMRI results were extracted according to the MNI coordinate system, which is the template used for SPM. Finally, the MNI coordinates were converted to Talairach space using the Talairach Software (University of Texas Health Science Center, San Antonio, TX).

\section{Analysis of DCM Processing}

We used the DCM technique in the SPM 12 toolbox to identify mutual influences among the neural substrates involved in anger processing (Friston et al., 2003). Specifically, the DCM enabled us to identify regional effects in terms of changing patterns of connectivity among the areas in relation to the experimentally-induced contextual modulation of connection strengths among the regions of interest (ROIs, Mazzola et al., 2016). Based on the findings of previous neuroimaging studies on anger processing and the results of the conventional analysis, three ROIs were defined in the following regions: the left anterior insula, the left STG, and the left OFC (see Table 1, Lindquist et al., 2012; Murphy et al., 2003; Phan et al., 2002; Wager et al., 2008). The BOLD time series data were extracted as the first eigenvariates of all significant voxels within a $5 \mathrm{~mm}$ radius sphere centered on each participant's local maxima in each ROI, as obtained from the results of the group analysis (anger-evoking condition vs. neutral condition).

Our DCM design matrices included regressor modeling of the effect of anger (anger-evoking condition) among the three regions including the insula, the STG, and the OFC. We created a subset of eight models based on our results and those of previous studies (see Figure 3, Deen, Pitskel, \& Pelphrey, 2010; Mazzola et al., 2016; Mesulam \& Mufson, 1982). In each subject, a DCM was specified with bidirectional and intrinsic connectivity among the three regions. Tract-tracing and resting-state fMRI have shown that the anterior insula has reciprocal connections with superior temporal areas and the OFC; these areas comprise the insulo-orbito-temporal network in the paralimbic brain (Deen et al., 2010; Mazzola et al., 2016). Recently, a study on the functional connectivity between the STG and the insula during anger processing also supported is the existence of a reciprocal connectivity between these areas. Therefore, in all models for the study, the left insula had bidirectional connections with the STG, corresponding to anatomical and functional evidence for connections between the two areas (Deen et al., 2010; Mazzola et al., 2016; Mesulam \& Mufson, 1982). Yet, functional connectivities between the insula - OFC and the STG - OFC during anger processing were not found. Eight model variants were then produced by setting an information conductance pattern, involving factors such as connectivity (parallel, serial, or full) and directionality (unidirectional or bidirectional) between the insula - OFC and the STG - OFC. In all models, the left STG received all anger-inducing conditions as a driving input.

After estimation, model comparison was implemented using random-effects Bayesian model selection (BMS) to compute exceedance and posterior probabilities at the group level (Kasess et al., 2010; Penny, Stephan, Mechelli, \& Friston, 2004; Stephan, Penny, Daunizeau, Moran, \& Friston, 2009). A Bayesian model average (BMA) analysis was then performed to infer the model structure (i.e., the significant connections between the ROIs) and the connectivity parameters among the groups. These values were entered to the within-group analysis for individual connections using one sample $t$-tests with false discovery rate (FDR) correction.

\section{RESULTS}

\section{Subject Reporting}

The concordance rate (positive anger responses to anger-evoking films) of the pictures presented was $74 \pm 8.40 \%$. The average intensity of anger induced by anger-evoking films, rated on a 6-point scale, was $3.86 \pm 0.72$ points

\section{Conventional fMRI Analysis}

To examine brain areas specifically related to anger processing, BOLD responses were contrasted between the anger-evoking and neutral conditions. Enhanced activation was observed in the bilateral middle occipital gyrus (Brodmann areas [BAs] 18 and 19), fusiform gyrus (BA 37), left OFC (BA 47), bilateral anterior temporal cortex, left insula, bilateral globus pallidus, left thalamus, and amygdala in the anger-evoking compared to the neutral condition (FWE-corrected $p<.05$ at voxel-level with a minimum cluster size of $k=10$; see Table 1 and Figure 2). No region exhibited a higher BOLD signal in the neutral condition than in the anger-evoking condition.

TABLE 1.

Coordinates and $t$ Scores for the Activated Areas

\begin{tabular}{cccccc}
\hline \multirow{2}{*}{ L/R } & \multirow{2}{*}{ Region } & \multicolumn{3}{c}{ Talairach coordinates } & \multirow{2}{*}{$\boldsymbol{t}$ value } \\
\cline { 3 - 5 } & & $\mathbf{X}$ & $\mathbf{Y}$ & $\mathbf{Z}$ & \\
\hline \multirow{2}{*}{$\mathrm{L}$} & \multirow{2}{*}{ Middle occipital gyrus } & -30 & -92 & -2 & 5.44 \\
& & 25 & -75 & -2 & 5.28 \\
$\mathrm{H} / \mathrm{R}$ & Fusiform gyrus & -50 & -58 & -20 & 5.31 \\
& & 48 & -50 & -16 & 5.68 \\
$\mathrm{~L}$ & Orbitofrontal cortex & -48 & 36 & -4 & $6.75^{*}$ \\
$\mathrm{~L} / \mathrm{R}$ & Superior temporal & -62 & -20 & 2 & $6.49^{*}$ \\
& cortex & 64 & 2 & -6 & 6.20 \\
$\mathrm{~L}$ & Insula & -32 & 16 & 12 & $6.73^{*}$ \\
$\mathrm{~L} / \mathrm{R}$ & Putamen & -22 & 10 & -6 & 5.77 \\
& & 15 & -7 & 2 & 5.49 \\
$\mathrm{~L}$ & Thalamus & -19 & -19 & 14 & 5.12 \\
$\mathrm{~L}$ & Amygdala & -17 & -6 & -9 & 4.99 \\
\hline
\end{tabular}

Note. $\mathrm{L}=$ left; $\mathrm{R}=$ right; $^{*}=$ the peaks used for the dynamic causal modeling with an asterisk. Anger condition $>$ Neutral condition; $p<.05$, corrected for Familywise error rate at at voxel-level with a minimum cluster size of $k=10$ 


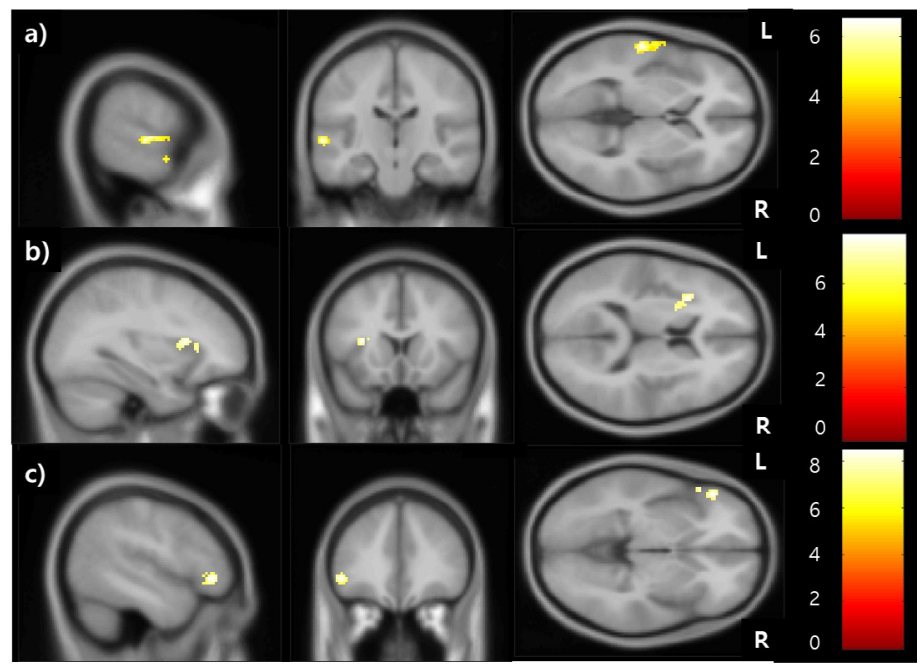

\section{FIGURE 2.}

Regions of interest for the dynamic causal models. Panel A: Left superior temporal gyrus ( $X, Y, Z$ coordinates: -62, -20, 2). Panel B: Left insula $(-32,16,12)$. Panel C: Left orbitofrontal cortex $(-48,36,-4)$. Maps were thresholded at $p<.05$ (family-wise error rate-corrected at voxel-level) with a minimum cluster size of $k=10$.
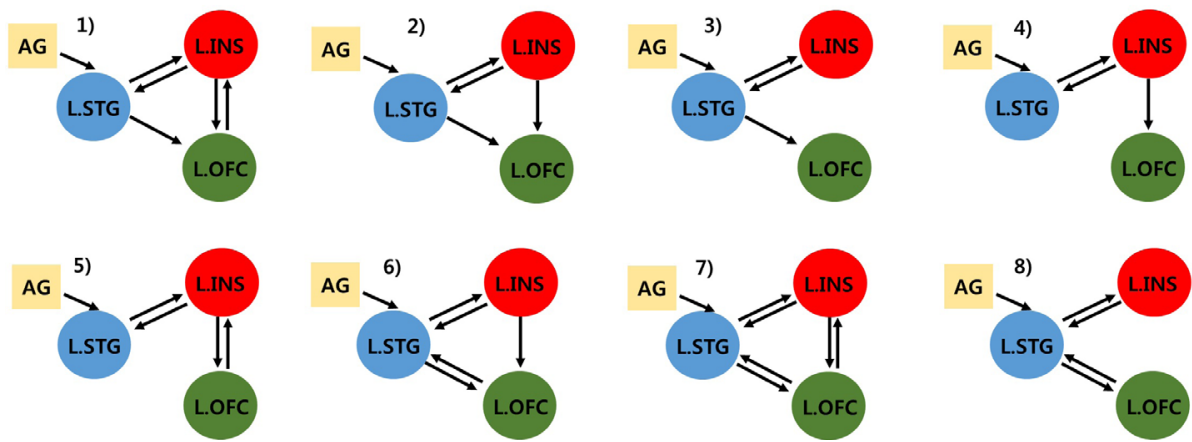

\section{FIGURE 3.}

Subset of eight models for the dynamic causal modeling analysis. AG = anger influence; L. INS = left insula; L. OFC = left orbitofrontal cortex; L. STG = left superior temporal gyrus.

|FIGURE 4.

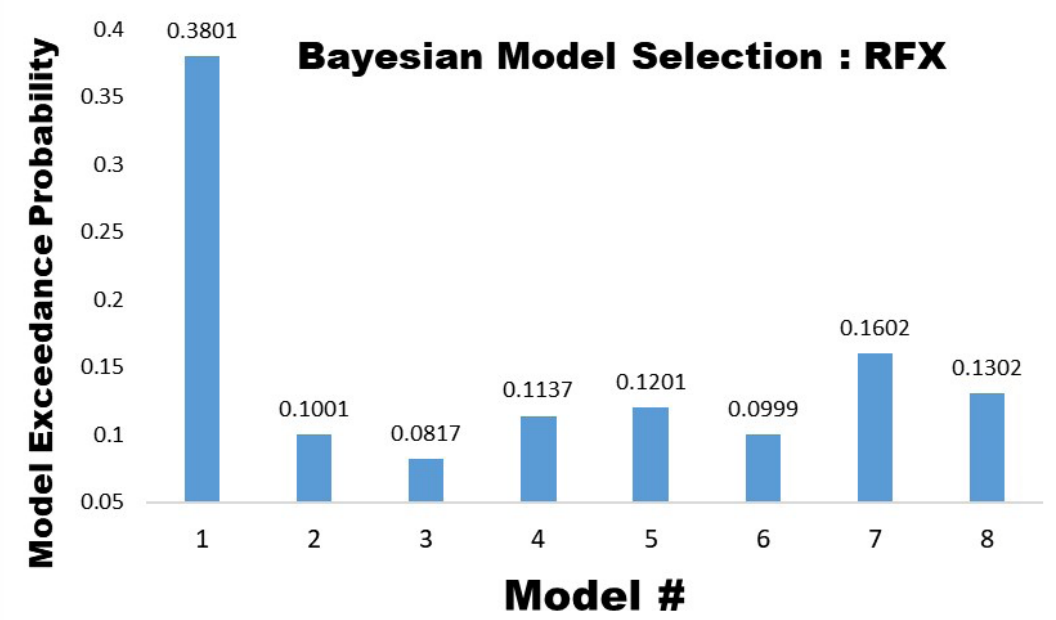

The results of Bayesian model selection. 


\section{Dynamic Causal Modeling Analysis}

We identified effective connectivity among the left anterior insula, left OFC, and left STG by modeling the extracted time course using DCM (see Table 1). Figure 4 shows the results of comparisons among eight dynamic causal models using BMS. With the Bayesian approach, it is commonly presumed that the optimal predictive model is the model with the highest posterior probability (Barbieri \& Berger, 2004). In group BMS, Model 1 was optimal, with the highest posterior probability (38.01\%). This winning model consisted of reciprocal effective connectivities between the left insula and the left STG as well as the left OFC, and also included bottom-up connectivity from the left STG to the left OFC.

To determine parameter estimates among the regions of Model 1, effective connectivity strengths of neuronal coupling were calculated using the BMA. Table 2 summarizes the BMA results and effective connectivities among the ROIs across all subjects and models (Corrected FDR at $p<.05$ ). Figure 5 shows a compatible architecture specifying intrinsic connections during anger processing. The solid and thick solid lines define significant $(p<.05)$, and very significant $(p<.01 ; p<.001)$ connections, respectively. The intrinsic coupling parameters shown in the figure represent the endogenous coupling strengths between source areas and targets corresponding to frequencies in $\mathrm{Hz}$. The coupling strength was strongest between the left STG and the left insula. A positive parameter indicates an enhancing influence of the origin region on the target region, whereas a negative parameter indicates that an increase in activity in the source region results in decreased activity in the target region (Mechelli, Price, Noppeney, \& Friston, 2003). That is, increased activity in the left STG led to increased activity in the left insula and left OFC. Activation of the left insula also enhanced activation of the STG. In contrast, increased activity in the left OFC (or left insula) diminished activity in the left insula (and left OFC)

\section{DISCUSSION}

In the present study, we expand on previous evidence from recently published studies on anger processing (Lindquist et al., 2012; Murphy et al., 2003; Phan et al., 2002; Wager et al., 2008). We identified a neural network subserving the processing of anger that includes connectivity between the left insula, left STG, and left OFC, as well as bottom-up connectivity between the left STG and left OFC.
The results of our conventional analysis are consistent with the findings of previous neuroimaging studies on anger processing (Lindquist et al., 2012; Murphy et al., 2003; Phan et al., 2002; Wager et al., 2008); we identified activity related to the experience of anger in various areas including the fusiform gyrus, amygdala, putamen, OFC, anterior insula, and STG. These regions are known to be related to emotion processing functions such as facial recognition, emotional perception, experience, regulation, and reaction (Adolphs, 2002). The bilateral middle occipital lobe including the fusiform gyrus is reportedly linked to the recognition and determination of a stimulus as emotional. According to previous studies on the emotions induced by visual stimuli, the occipital lobe including the fusiform gyrus is activated to a greater extent when emotional rather than nonemotional visual stimuli are presented, due to increased attention (Corbetta, Miezin, Dobmeyer, Shulman, \& Petersen, 1991; Lane, Reiman, Ahern, Schwartz, \& Davidson, 1997; Lane, Reiman, Bradley et al., 1997). Evidence from animal studies (Maeda, Morimoto, \& Yanagimoto, 1993; Ono \& Nishijo, 1992), lesion studies (Aggleton \& Young, 2000), and neuroimaging studies (Morris, Öhman, \& Dolan, 1998; Whalen et al., 1998) has suggested that the amygdala is not involved in the perception of basic sensory stimuli but in the subliminal perception of emotional stimuli, which specifically includes the decoding of emotional reactions corresponding to their significance. The putamen is one of the structures that comprises the basal ganglia, and it is known to be associated with motor control, cognition, emotion, and somatosensory functions (Arsalidou, Duerden, \& Taylor, 2013). According to previous studies, the putamen is associated with the recognition of emotional facial expressions (Calder, Keane, Manes, Antoun, \& Young, 2000, Calder, Keane, Lawrence, \& Manes, 2004; Phillips et al., 1998). Among the activated regions, the STG, anterior insula, and OFC are thought to be functionally specialized for the processing of anger. Based on our study findings and the known roles of these areas, we speculate that anger processing involves interactions among the left insula, left STG, and left OFC.

We used the DCM to determine intrinsic connections between our target areas and identified strong endogenous connectivity between the left STG and left insula across all subjects. This result reaffirmed a previously reported parallel pattern of connectivity between the STG and insula for the recognition and processing of angry faces (Mazzola et al., 2016).

Numerous noninvasive brain stimulation and neuroimaging studies have investigated the functions of the STG. These studies have con-

TABLE 2.

Estimated Coupling Paramenters Among Regions of Interest

\begin{tabular}{|c|c|c|c|c|c|c|c|}
\hline \multicolumn{2}{|c|}{ Areas } & \multirow{2}{*}{ Mean } & \multirow{2}{*}{ SD } & \multirow{2}{*}{ Maximum } & \multirow{2}{*}{ Minimum } & \multirow{2}{*}{ Median } & \multirow{2}{*}{$p$ value } \\
\hline Origin & Target & & & & & & \\
\hline Superior temporal gyrus & Anterior insula & 0.32 & 0.13 & 0.67 & 0.13 & 0.31 & $<.001$ \\
\hline Anterior insula & Superior temporal gyrus & 0.17 & 0.06 & 0.28 & 0.04 & 0.16 & $<.01$ \\
\hline Superior temporal gyrus & Orbitofrontal gyrus & 0.13 & 0.09 & 0.27 & -0.02 & 0.13 & $<.05$ \\
\hline Anterior insula & Orbitofrontal gyrus & -0.05 & 0.05 & 0.04 & -0.15 & -0.04 & $<.001$ \\
\hline Orbitofrontal gyrus & Anterior insula & -0.07 & 0.05 & -0.01 & -0.16 & -0.06 & $<.001$ \\
\hline
\end{tabular}

Note. Difference significant at $p<.05$ (Bonferroni corrected for multiple comparisons). 


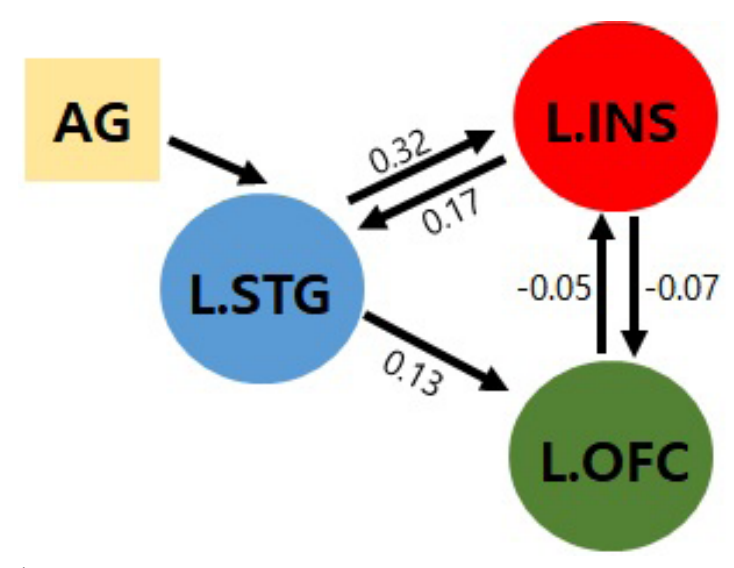

FIGURE 5.

Connectivity strength of the winning model.

sistently associated task-related STG activation with anger processing (Frühholz \& Grandjean, 2012; Mazzola et al., 2016; Sander et al., 2005). Activation in the STG was reported during decoding of angry vocal expressions, angry voice prosody processing (Frühholz \& Grandjean, 2012; Sander et al., 2005), and anger-inducing situations (Allison et al., 2000; Xu et al., 2009). The STG is involved in processing a diverse array of socially-salient stimuli, such as those derived from other individuals' faces, voices, gestures, and contextual information (Allison et al., 2000; Mazzola et al., 2016; Mechelli et al., 2003; Singer et al., 2004; Xu et al., 2009). Other neuroimaging evidence suggests that dysfunction of the STG plays a role in psychiatric disorders involving impairment of social cognition and social functioning, such as autism spectrum disorder and schizophrenia (Cheng, Rolls, Gu, Zhang, \& Feng, 2015; Green, \& Leitman, 2008; Mazzola et al, 2016).

The anterior insula is thought to be involved in the awareness of bodily sensations, interoception, and the awareness of affective feelings (Adolphs, 2002; Craig, 2009). Bodily sensations can be experienced as states with some level of emotional arousal. A previous meta-analysis determined that activation of the left anterior insula was consistently increased during the experience of anger, compared to any other emotional category (Lindquist et al., 2012). A human neuroimaging study using diffusion tensor imaging found that the anterior insula is interconnected to regions of the OFC (Craig, 2009). Consistent with this study, we identified functional connectivity between the left insula and the OFC. Additionally, the left insula and the OFC exhibited inverse patterns of activation; this result partially supports the findings of a previous study on connectivity between the OFC and the insula during high-level threat processing (Barbas, 1995; Lim, Padmala, \& Pessoa, 2008; Pessoa, 2009). Although the OFC is a large structure that is undoubtedly associated with other psychological phenomena, previous meta-analyses of neuroimaging literature have proposed a primary role for the OFC in anger (Lindquist et al., 2012; Murphy et al., 2003; Vytal \& Hamann, 2010). The OFC influences affect by integrating exteroceptive (information from the world) and interoceptive (information from the body) sensations to guide behavior (Lindquist et al., 2012), such that individuals with damage to the OFC exhibit an inability to integrate exteroceptive and interoceptive sensory information, resulting in inappropriate behavior and aggression (Bechara et al., 2000; Grafman et al., 1996). Indeed, individuals with psychopathy traits and antisocial personality disorder featuring increased aggression show changes in the function and structure of the OFC (Glenn \& Raine, 2009; Harenski, Kim, \& Hamann, 2009; Raine, 2002; Yang \& Raine, 2009). Taken together, these findings and our results support a clear role for the OFC in anger as a center for the integration of multimodal sensations.

One of the most interesting findings was a dominant model including one positive reciprocal connectivity (i.e., insula - STG) and one negative reciprocal connectivity (i.e., insula - OFC). The results showed that mutual inhibition between elaborative processing (in the left OFC) and affective awareness (in the left insula) is involved in emotional processing. Electroencephalographic (Harmon-Jones \& Allen, 1998; Harmon-Jones \& Sigelman, 2001) and functional neuroimaging (Blair, Morris, Frith, Perrett, \& Dolan, 1999; Damasio et al., 2000; Dougherty et al., 1999; Kimbrell et al., 1999; Pietrini, Guazzelli, Basso, Jaffe, \& Grafman, 2000) studies have used emotion induction paradigms to examine the neural substrates associated with anger in healthy subjects. Although these studies used different techniques to induce anger, all have revealed the involvement of common anterior paralimbic structures for emotional experiences together with the prefrontal cortex (PFC), including the OFC for cognitive processing, during anger states. This finding showed that several regions of the PFC, including the OFC, play a crucial role in constraining impulsive outbursts (Davidson, Putnam, \& Larson, 2000; Goldin, McRae, Ramel, \& Gross 2008). Thus, it is proposed that cognitive processing and emotional experiences are separated in anger processing. The negative reciprocal connectivity (i.e., insula - OFC) revealed in the current study is also consistent with the general understanding about the role of the OFC in cognitive control of negative emotion.

Understanding effective connectivity during anger processing may advance investigations in patients with violent outbursts and aggressive acts, including those with intermittent explosive disorder and borderline personality disorder. Recently, Lee et al. (2016) found a subtle disruption of the long-range white matter tracks connecting the parietal and temporal lobes to the frontal cortex in intermittent explosive disorder patients. This result provides the first evidence of altered brain connectivity in people with anger-related disorders. However, they only showed a difference in anatomical connectivity, not in functional connectivity during the actual experience of anger. Hence, our effective connectivity model could be applied to identify functional dysconnectivity among such patients.

The present study has some limitations. First, our study does not address known sex differences in brain engagement during threat evaluation and the emotional perception of anger (McClure et al., 2004; Sabatinelli, Flaisch, Bradley, Fitzsimmons, \& Lang, 2004), as we only included male subjects. Second, we cannot exclude the possible confounding effects of other factors such as motivation and cognition on our results. Thus, some ROIs activated in our study may have roles more directly related to motivation and cognition than to anger. Third, some brain areas known to play an important role in anger (i.e., the amygdala and putamen) were excluded from the DCM analysis. 
Previous neuroimaging studies have suggested the specificity of these areas for negative emotion, including fear and anger. We also found activation in these areas during anger processing in the within-group analyses. However, the activation found in the group analysis does not signify that these areas were activated in each participant. To construct the individual model for the DCM analysis, the brain areas that are activated over a threshold should be included, with the threshold usually being determined by a researcher. Some participants did not show significant activation in the amygdala at a lower statistical threshold $(p<.001$, uncorrected). For this reason, the amygdala was excluded from the analysis in our study. Fourth, in previous studies, the right insula appeared to have a dominant role in emotional processing. However, in a recent study using quantitative meta-analytic methods, emotional stimuli predominantly activated the left anterior insula in men, whereas the bilateral anterior insula was activated in women (Duerden, Arsalidou, Lee, \& Taylor, 2013). In this study, only the left insula was activated, possibly because we only included male participants. However, there is debate regarding the lateralization of affective processing in the insula. In further studies, we would like to consider this lateralization by examining other factors such as sex. Finally, to remove any confounding effects, we attempted to render the two types of film clips as similar as possible (i.e., in color and hue). However, due to their emotional characteristics, the levels of arousal and valence were not matched. Hence, the differences in brain responses between the two types of clips might be attributable not only to differences in elicited emotions (i.e., anger stimuli vs. neutral stimuli), but also to arousal and valence.

Even so, it is noteworthy that our results are consistent with those of previous studies on anger processing indicating important roles for the insula, STG, and OFC. Furthermore, the results have various implications by providing evidence that anger processing is modulated by affective awareness and cognitive regulation based on different couplings between the insula - STG and the insula - OFC. The results suggest that anger processing may depend on a more direct interaction between a system related to the regulation of emotion (i.e., the OFC) and a system associated with generating anger (i.e., the insula).

\section{CONCLUSION}

We have created a dynamic causal model to identify how the brain areas associated with emotional processing (i.e., emotional perception, experience, and regulation) meditate each other during anger processing. Our results should facilitate future investigations of anger processing in various psychiatric disorders, such as borderline personality disorder and intermittent explosive disorder, which are accompanied by abnormalities in emotional perception and regulation.

\section{COMPETING INTERESTS}

The authors have declared that no competing interests exist.

\section{AUTHORS' CONTRIBUTIONS}

JWS made substantial contributions to conception and design, acquisition of the data, and analysis and interpretation of the data. JWS and CC were involved in drafting the manuscript and revising it critically for important intellectual content. All authors gave final approval of the version to be published.

\section{ACKNOWLEDGEMENTS}

This work was supported by the Ministry of Education of the Republic of Korea and the National Research Foundation of Korea (NRF-2015S1A5B5A01015896).

\section{REFERENCES}

Adolphs, R. (2002). Neural systems for recognizing emotion. Current Opinion in Neurobiology, 12, 169-177. doi:10.1016/ S0959-4388(02)00301-X المبلسليسلة

Adolphs, R. (2003). Cognitive neuroscience of human social behavior. Nature Reviews Neuroscience, 4, 165-178. doi:10.1038/ nrn1056 السلسلس

Aggleton, J. P., \& Young, A. W. (2000). The enigma of the amygdala: On its contribution to human emotion. In R. D. Lane \& L. Nadel (Eds.), Series in affective science. Cognitive neuroscience of emotion, (pp. 106-128). New York City, NY: Oxford University Press.

Allison, T., Puce, A., \& McCarthy, G. (2000). Social perception from visual cues: role of the STS region. Trends in Cognitive Sciences,

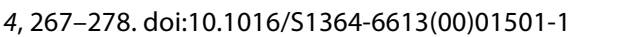

Arsalidou, M., Duerden, E. G., \& Taylor, M. J. (2013). The centre of the brain: Topographical model of motor, cognitive, affective, and somatosensory functions of the basal ganglia. Human Brain Mapping, 34, 3031-3054. doi:10.1002/hbm.22124 الم السلكا

Bakke, L. A. W. (2012). Effective connectivity within a core cortical network of face perception: evidence for inferior occipital gyrus sensitivity for faces with implicit emotions [Master's thesis, University of Oslo, Norway].

Baldwin, M. W. (1992). Relational schemas and the processing of social information. Psychological Bulletin, 112, 461-484. doi:10.1037/0033-2909.112.3.461 البلسلسلس

Barbas, H. (1995). Anatomic basis of cognitive-emotional interactions in the primate prefrontal cortex. Neuroscience \& Biobehavioral Reviews, 19, 499-510. doi:10.1016/01497634(94)00053-4 سلس

Barbieri, M. M., \& Berger, J. O. (2004). Optimal predictive model selection. Annals of Statistics, 32, 870-897. doi:10.1214/009053604000000238

Bechara, A., Damasio, H., \& Damasio, A. R. (2000). Emotion, decision making and the orbitofrontal cortex. Cerebral Cortex, 10,

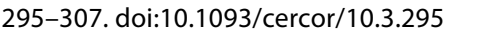

Blair, R. J. R., Morris, J. S., Frith, C. D., Perrett, D. I., \& Dolan, R. J. (1999). Dissociable neural responses to facial expressions of sadness and anger. Brain, 122, 883-893. doi:10.1093/ brain/122.5.883 |لسلبل 
Calder, A. J., Keane, J., Lawrence, A. D., \& Manes, F. (2004). Impaired recognition of anger following damage to the ventral striatum. Brain, 127, 1958-1969. doi:10.1093/brain/awh214 السلبلسلس

Calder, A. J., Keane, J., Manes, F., Antoun, N., \& Young, A. W. (2000). Impaired recognition and experience of disgust following brain injury. Nature Neuroscience, 3, 1077. doi:10.1038/80586 المالسلس

Cheng, W., Rolls, E. T., Gu, H., Zhang, J., \& Feng, J. (2015). Autism: Reduced connectivity between cortical areas involved in face expression, theory of mind, and the sense of self. Brain, 138, 1382-1393. doi:10.1093/brain/awv051 سلس

Corbetta, M., Miezin, F. M., Dobmeyer, S., Shulman, G. L., \& Petersen, S. E. (1991). Selective and divided attention during visual discriminations of shape, color, and speed: functional anatomy by positron emission tomography. The Journal of Neuroscience, 11, 2383-2402. doi:10.1523/JNEUROSCI.11-08-02383.1991 السلسلسلس

Craig, A. D. (2009). How do you feel-now? The anterior insula and human awareness. Nature Reviews Neuroscience, 10, 59-70. doi:10.1038/nrn2555 المسلسلس

Critchley, H. D. (2009). Psychophysiology of neural, cognitive and affective integration: $\mathrm{fMRI}$ and autonomic indicants. International Journal of Psychophysiology, 73, 88-94. doi:10.1016/j.ijpsycho.2009.01.012 1. 16

Damasio, A. R., Grabowski, T. J., Bechara, A., Damasio, H., Ponto, L. L., Parvizi, J., \& Hichwa, R. D. (2000). Subcortical and cortical brain activity during the feeling of self-generated emotions. Nature Neuroscience, 3, 1049-1056. doi:10.1038/79871 المالسليلكا.

Davidson, R. J., Putnam, K. M., \& Larson, C. L. (2000, July). Dysfunction in the neural circuitry of emotion regulation-a possible prelude to violence. Science, 289, 591-594. doi:10.1126/science.289.5479.591 الس الس

Deen, B., Pitskel, N. B., \& Pelphrey, K. A. (2010). Three systems of insular functional connectivity identified with cluster analysis.

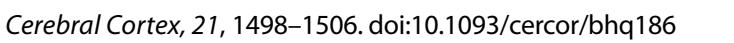

Denson, T. F., Pedersen, W. C., Ronquillo, J., \& Nandy, A. S. (2009) The angry brain: Neural correlates of anger, angry rumination, and aggressive personality. Journal of Cognitive Neuroscience, 21, 734-744. doi:10.1162/jocn.2009.21051 المسلسلس

Dougherty, D. D., Shin, L. M., Alpert, N. M., Pitman, R. K., Orr, S. P., Lasko M., ..., Rauch S.L. (1999). Anger in healthy men: A PET study using script-driven imagery. Biological Psychiatry, 46, 466-472. doi:10.1016/S0006-3223(99)00063-3 سلس

Duerden, E. G., Arsalidou, M., Lee, M., \& Taylor, M. J. (2013). Lateralization of affective processing in the insula. Neuroimage, 78, 159-175. doi:10.1016/j.neuroimage.2013.04.014 السالسلسل|

Fairhall, S. L., \& Ishai, A. (2006). Effective connectivity within the distributed cortical network for face perception. Cerebral Cortex, 17, 2400-2406. doi:10.1093/cercor/bhl148 السلبلسلسا

First, M. B., Spitzer, R. L., \& Gibbon, M. (2002). Structured clinical interview for DSM-IV-TR axis I disorders-non-patient edition (SCID-I/NP, 11/2002 Revision). New York City, NY: Biometric Research Department, New York State Psychiatric Institute.

Friston, K. J. (1994). Functional and effective connectivity in neuroimaging: A synthesis. Human Brain Mapping, 2, 56-78. doi:10.1002/hbm.460020107 المالسلسلة

Friston, K. J., Harrison, L., \& Penny, W. (2003). Dynamic causal modelling. Neuroimage, 19, 1273-1302. doi:10.1016/S10538119(03)00202-7 سلس

Frühholz, S., \& Grandjean, D. (2012). Towards a fronto-temporal neural network for the decoding of angry vocal expressions. Neuroimage, 62, 1658-1666. doi:10.1016/j.neuroim-

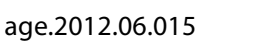

Glenn, A. L., \& Raine, A. (2009) Psychopathy and instrumental aggression: Evolutionary, neurobiological, and legal perspectives. International Journal of Law and Psychiatry, 32, 253-258. doi:10.1016/j.ijlp.2009.04.002 السلسلس

Goldin, P. R., McRae, K., Ramel, W., \& Gross, J. J. (2008) The neural bases of emotion regulation: Reappraisal and suppression of negative emotion. Biological Psychiatry, 63, 577-586. doi:10.1016/j.biopsych.2007.05.031 السلسلس

Grafman, J., Schwab, K., Warden, D., Pridgen, A., Brown, H. R., \& Salazar, A. M. (1996). Frontal lobe injuries, violence, and aggression a report of the Vietnam head injury study. Neurology, 46, 1231-1231. doi:10.1212/WNL.46.5.1231 المسلسلسلس

Green, M. F., \& Leitman, D. I. (2008). Social cognition in schizophrenia. Schizophrenia Bulletin, 34, 670-672. doi:10.1093/ schbul/sbn045 سلس

Gu, X., Hof, P. R., Friston, K. J., \& Fan, J. (2013). Anterior insular cortex and emotional awareness. Journal of Comparative Neurology, 521, 3371-3388. doi:10.1002/cne.23368 المالسلس

Harenski, C. L., Kim, S. H., \& Hamann, S. (2009). Neuroticism and psychopathy predict brain activation during moral and nonmoral emotion regulation. Cognitive, Affective, \& Behavioral Neuroscience, 9, 1-15. doi:10.3758/CABN.9.1.1 السلسلس

Harmon-Jones, E., \& Allen, J. J. (1998). Anger and frontal brain activity: EEG asymmetry consistent with approach motivation despite negative affective valence. Journal of Personality and Social Psychology, 74, 1310-1316. doi:10.1037/00223514.74.5.1310 سلس

Harmon-Jones, E., \& Sigelman, J. (2001). State anger and prefrontal brain activity: Evidence that insult-related relative leftprefrontal activation is associated with experienced anger and aggression. Journal of Personality and Social Psychology, 80, 797-803. doi:10.1037/0022-3514.80.5.797 الس السلس

Hemenover, S. H., \& Schimmack, U. (2007). That's disgusting!..., but very amusing: Mixed feelings of amusement and disgust. Cognition and Emotion, 21, 1102-1113. doi:10.1080/02699930601057037 الس

Horwitz, B. (2003). The elusive concept of brain connectivity.

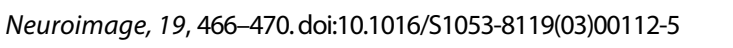
Kasess, C. H., Stephan, K. E., Weissenbacher, A., Pezawas, L., Moser, E., \& Windischberger, C. (2010). Multi-subject analyses with dynamic causal modeling. Neuroimage, 49, 3065-3074. doi:10.1016/j.neuroimage.2009.11.037 المالس

Kimbrell, T. A., George, M. S., Parekh, P. I., Ketter, T. A., Podell, D. 
M., Danielson, A. L., ... \& Post, R. M. (1999). Regional brain activity during transient self-induced anxiety and anger in healthy adults. Biological Psychiatry, 46, 454-465. doi:10.1016/S00063223(99)00103-1 سلس

Lampert, R. (2016). Behavioral influences on cardiac arrhythmias. Trends in Cardiovascular Medicine, 26, 68-77. doi:10.1016/j. tcm.2015.04.008 الس الس

Lampert, R., Joska, T., Burg, M. M., Batsford, W. P., McPherson, C. A., \& Jain, D. (2002). Emotional and physical precipitants of ventricular arrhythmia. Circulation, 106, 1800-1805. doi:10.1161/01.CIR.0000031733.51374.C1 الس السلس

Lane, R. D., Reiman, E. M., Ahern, G. L., Schwartz, G. E., \& Davidson, R. J. (1997). Neuroanatomical correlates of happiness, sadness, and disgust. American Journal of Psychiatry, 154, 926-933. doi:10.1176/ajp.154.7.926 الس

Lane, R. D., Reiman, E. M., Bradley, M. M., Lang, P. J., Ahern, G. L., Davidson, R. J., \& Schwartz, G. E. (1997). Neuroanatomical correlates of pleasant and unpleasant emotion. Neuropsychologia, 35, 1437-1444. doi:10.1016/S0028-3932(97)00070-5 سلس

Larsen, J. T., McGraw, A. P., \& Cacioppo, J. T. (2001). Can people feel happy and sad at the same time? Journal of Personality and Social Psychology, 81, 684-696. doi:10.1037/00223514.81 .4 .684 (1)

LeDoux, J. E. (1989). Cognitive-emotional interactions in the brain. Cognition \& Emotion, 3, 267-289. doi:10.1080/02699938908412709 \&لسلسلس

Lee, R., Arfanakis, K., Evia, A. M., Fanning, J., Keedy, S., \& Coccaro, E. F. (2016). White matter integrity reductions in intermittent explosive disorder. Neuropsychopharmacology, 41, 2697-2703. doi:10.1038/npp.2016.74 الس السلس

Lemerise, E. A., \& Arsenio, W. F. (2000). An integrated model of emotion processes and cognition in social information processing. Child Development, 71, 107-118. doi:10.1111/14678624.00124 إلس

Lim, S. L., Padmala, S., \& Pessoa, L. (2008). Affective learning modulates spatial competition during low-load attentional conditions. Neuropsychologia, 46, 1267-1278. doi:10.1016/j.

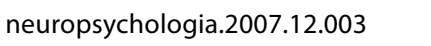

Lindquist, K.A., Wager, T.D., Kober, H., Bliss-Moreau, E., \& Barrett, L.F. (2012). The brain basis of emotion: A meta-analytic review. Behavioral and Brain Sciences, 35, 121-143. doi:10.1017/ S0140525X11000446 الس الس

Maeda, H., Morimoto, H., \& Yanagimoto, K. (1993). Response characteristics of amygdaloid neurons provoked by emotionally significant environmental stimuli in cats, with special reference to response durations. Canadian Journal of Physiology

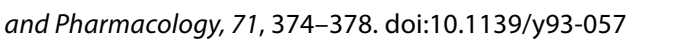

Mazzola, V., Arciero, G., Fazio, L., Lanciano, T., Gelao, B., Popolizio, T., ... \& Bertolino, A. (2016). What impact does an angry context have upon us? The effect of anger on functional connectivity of the right insula and superior temporal gyri. Frontiers in Behavioral Neuroscience, 10, 109. doi:10.3389/fn-

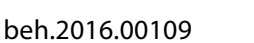

McArthur, L. Z., \& Baron, R. M. (1983). Toward an ecological theory of social perception. Psychological Review, 90, 215-238. doi:10.1037/0033-295X.90.3.215 الس الس

McClure, E. B., Monk, C. S., Nelson, E. E., Zarahn, E., Leibenluft, E., Bilder, R. M., ... \& Pine, D. S. (2004). A developmental examination of gender differences in brain engagement during evaluation of threat. Biological Psychiatry, 55, 1047-1055. doi:10.1016/j.biopsych.2004.02.013 السلسلسلس

Mechelli, A., Price, C. J., Noppeney, U., \& Friston, K. J. (2003). A dynamic causal modeling study on category effects: bottom-up or top-down mediation? Journal of Cognitive Neuroscience, 15,

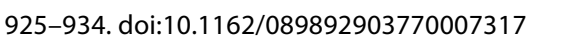

Mesulam, M. M., \& Mufson, E. J. (1982). Insula of the old world monkey. III: Efferent cortical output and comments on function. Journal of Comparative Neurology, 212, 38-52.

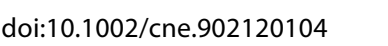

Morris, J. S., Öhman, A., \& Dolan, R. J. (1998). Conscious and unconscious emotional learning in the human amygdala. Nature, 393, 467-470. doi:10.1038/30976 المالسلسلس

Mostofsky, E., Penner, E. A., \& Mittleman, M. A. (2014). Outbursts of anger as a trigger of acute cardiovascular events: A systematic review and meta-analysis. European Heart Journal, 35, 1404-1410. doi:10.1093/eurheartj/ehu033 الس الس الس الس

Murphy, F. C., Nimmo-Smith, I., \& Lawrence, A. D. (2003). Functional neuroanatomy of emotions: A meta-analysis. Cognitive, Affective, \& Behavioral Neuroscience, 3, 207-233. doi:10.3758/CABN.3.3.207 سلس

Nagai, M., Hoshide, S., \& Kario, K. (2010). The insular cortex and cardiovascular system: A new insight into the brain-heart axis. Journal of the American Society of Hypertension, 4, 174-182. doi:10.1016/j.jash.2010.05.001

Novaco, R. W. (1976). The functions and regulation of the arousal of anger. American Journal of Psychiatry, 133, 1124-1128. doi:10.1176/ajp.133.10.1124

Ono, T., \& Nishijo, H. (1992). Neurophysiological basis of the Klüver-Bucy syndrome: Responses of monkey amygdaloid neurons to biologically significant objects. In J. P. Aggleton (Ed.), The amygdala: Neurobiological aspects of emotion, memory, and mental dysfunction (pp. 167-190). New York City, NY: Wiley-Liss.

Oppenheimer, S. (2006). Cerebrogenic cardiac arrhythmias: Cortical lateralization and clinical significance. Clinical Autonomic Research, 16, 6-11. doi:10.1007/s10286-006-0276-0 الس السلس

Paulus, M. P., Feinstein, J. S., Leland, D., \& Simmons, A. N. (2005). Superior temporal gyrus and insula provide response and outcome-dependent information during assessment and action selection in a decision-making situation. Neuroimage, 25 , 607-615. doi:10.1016/j.neuroimage.2004.12.055 السلسلسلس

Penny, W. D., Stephan, K. E., Mechelli, A., \& Friston, K. J. (2004). Comparing dynamic causal models. Neuroimage, 22, 11571172. doi:10.1016/j.neuroimage.2004.03.026 السلسلس 
Pessoa, L. (2009). How do emotion and motivation direct executive control? Trends in Cognitive Sciences, 13, 160-166. doi:10.1016/j.tics.2009.01.006 الس

Phan, K. L., Wager, T., Taylor, S. F., \& Liberzon, I. (2002). Functional neuroanatomy of emotion: A meta-analysis of emotion activation studies in PET and fMRI. Neuroimage, 16, 331-348. doi:10.1006/nimg.2002.1087 سلس

Phillips, M. L., Young, A. W., Scott, S., Calder, A. J., Andrew, C., Giampietro, V., ... \& Gray, J. A. (1998). Neural responses to facial and vocal expressions of fear and disgust. Proceedings of the Royal Society of London B: Biological Sciences, 265, 1809-1817. doi:10.1098/rspb.1998.0506 سلس

Pietrini, P., Guazzelli, M., Basso, G., Jaffe, K., \& Grafman, J. (2000). Neural correlates of imaginal aggressive behavior assessed by positron emission tomography in healthy subjects. American Journal of Psychiatry, 157, 1772-1781. doi:10.1176/appi. ajp.157.11.1772 السلسلسل

Raine, A. (2002). Annotation: The role of prefrontal deficits, low autonomic arousal, and early health factors in the development of antisocial and aggressive behavior in children. Journal of Child Psychology and Psychiatry, 43, 417-434. doi:10.1111/1469-7610.00034 السلسلس

Sabatinelli, D., Flaisch, T., Bradley, M. M., Fitzsimmons, J. R., \& Lang, P. J. (2004). Affective picture perception: gender differences in visual cortex? Neuroreport, 15, 1109-1112.

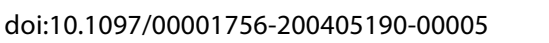

Schaefer, A., Nils, F., Sanchez, X., \& Philippot, P. (2010). Assessing the effectiveness of a large database of emotion-eliciting films: A new tool for emotion researchers. Cognition and Emotion, 24, 1153-1172. doi:10.1080/02699930903274322 سلس الس

Sander, D., Grandjean, D., Pourtois, G., Schwartz, S., Seghier, M. L., \& Scherer, K. R. (2005). Emotion and attention interactions in social cognition: Brain regions involved in processing anger prosody. Neurolmage, 28, 848-858. doi:10.1016/j.neuroimage.2005.06.023 السلسلس

Schimmack, U. (2001). Pleasure, displeasure, and mixed feelings: Are semantic opposites mutually exclusive? Cognition \& Emotion, 15, 81-97. doi:10.1080/02699930126097 السلسلسلس

Singer, T., Kiebel, S. J., Winston, J. S., Dolan, R. J., \& Frith, C. D. (2004). Brain responses to the acquired moral status of faces. Neuron, 41, 653-662. doi:10.1016/S0896-6273(04)00014-5 الس Stephan, K. E., Weiskopf, N., Drysdale, P. M., Robinson, P. A., \&
Friston, K. J. (2007). Comparing hemodynamic models with DCM. Neuroimage, 38, 387-401. doi:10.1016/j.neuroimage.2007.07.040 السلسلس

Stephan, K. E., Penny, W. D., Daunizeau, J., Moran, R. J., \& Friston, K. J. (2009). Bayesian model selection for group studies. Neuroimage, 46, 1004-1017. doi:10.1016/j.neuroimage.2009.03.025 المسلسلس

Suls, J. (2013). Anger and the heart: perspectives on cardiac risk, mechanisms and interventions. Progress in Cardiovascular Diseases, 55, 538-547. doi:10.1016/j.pcad.2013.03.002 الس السلسلة

Taggart, P., \& Lambiase, P. (2011). Anger, emotion, and arrhythmias: from brain to heart. Frontiers in Physiology, 2, 67. doi:10.3389/fphys.2011.00067 السلسلس

Videbeck, S. (2013). Psychiatric-mental health nursing. Philadelphia, PA: Lippincott Williams \& Wilkins.

Vytal, K., \& Hamann S. (2010). Neuroimaging support for discrete neural correlates of basic emotions: a voxel-based metaanalysis. Journal of Cognitive Neuroscience, 22, 2864-2885. doi:10.1162/jocn.2009.21366 السلسلس

Wager, T. D., Barrett, L. F., Bliss-Moreau, E., Lindquist, K., Duncan, S., Kober, H., ... \& Mize, J. (2008). The neuroimaging of emotion. In M. Lewis, J. M. Haviland-Jones, L. F. Barrett (Eds.), Handbook of Emotions (pp. 249-271). New York City, NY: Guilford Press.

Whalen, P. J., Rauch, S. L., Etcoff, N. L., Mclnerney, S. C., Lee, M. B., \& Jenike, M. A. (1998). Masked presentations of emotional facial expressions modulate amygdala activity without explicit knowledge. Journal of Neuroscience, 18, 411-418. doi:10.1523/ JNEUROSCI.18-01-00411.1998 الس السلس

Xu, J., Gannon, P. J., Emmorey, K., Smith, J. F., Braun, A. R. (2009). Symbolic gestures and spoken language are processed by a common neural system. Proceedings of the National Academy of Sciences, 106, 20664-20669. doi:10.1073/pnas.0909197106 المسلسلس

Yang, Y., \& Raine, A. (2009). Prefrontal structural and functional brain imaging findings in antisocial, violent, and psychopathic individuals: A meta-analysis. Psychiatry Research:Neuroimaging, 174, 81-88. doi:10.1016/j.pscychresns.2009.03.012 سلسلس 